\title{
Understanding the Effects of COVID-19 on the Education of Low-Income Students in Khamariya, Nepal
}

\author{
Meghna Katyal ${ }^{1}$ and Andrea Charlton ${ }^{1 \#}$ \\ ${ }^{1}$ Havergal College, Toronto, Ontario, CA \\ \#Advisor
}

$\underline{\text { ABSTRACT }}$

This paper addresses the impacts COVID-19 is having on the learning of upper-primary students in a remote community in Nepal. These findings are based on interviews with 15 students in Khamariya- a small village with limited infrastructure and minimal access to technology. In this paper, the education system in Nepal before COVID-19 is discussed and compared with the current learning that is happening throughout the pandemic. The shortcomings of government solutions are discussed, the benefits of the pandemic on students' learning are evaluated, and the implications of changes in students' learning due to the pandemic are analyzed. Overall, through the interviews, it has been determined that the education system in remote communities in Nepal before the pandemic was below standard. However, COVID-19 is exacerbating these negative aspects of the education system even further. The pandemic is specifically targeting impoverished students' education. As well, it is increasing the gap between advantaged and disadvantaged students, which is contributing to the cycle of poverty.

\section{Introduction}

COVID-19 with a focus on Southern Asia

The COVID-19 pandemic has disrupted the education of 1.6 billion children across 191 countries (Dawadi et al., 2020). Due to the nature of the virus, it is extremely unsafe for students to congregate in educational institutions, such as schools and universities, as it may further contribute to the spread of the coronavirus. Consequently, many schools across the globe have been required to temporarily close and transition to online learning. While virtual education comes with its own limitations such as lack of social interaction and increased distractions during online classes, it at least allows students to continue learning throughout the pandemic. Unfortunately, this is not an option all children have access to. In fact, approximately 144 million students in South Asia (38\%) are unable to learn remotely (Farid et al., 2021). This issue is further exacerbated in low-income, impoverished countries with overburdened schools. Many public schools in Southern Asia do not have the infrastructure to provide students with tablets or laptops, and most economically unstable students do not own personal computers. As a result, many schools in Southern Asia do not have the capabilities to teach students online. To combat this, government bodies have implemented measures such as teaching through radio and television. While this is taking a stride in the correct direction, not all students have access to such technology. This is especially true in rural communities where there is limited electricity and unsteady Wi-Fi connection. In fact, "only 63\% of the households [in Nepal] have access to at least one technology" (Radhakrishnan et al., 2021). So, while middle-class and upper-class students who live in urban areas are likely obtaining some sort of education during the pandemic, lower-class students, especially in remote communities, have completely halted their learning. This has major implications for their short and long-term education. 
Moreover, the rising number of COVID-19 cases in Nepal is what caused the government to close all schools and universities throughout the country on March 18, 2020 (Farid et al., 2021). Even with lockdown, social distancing, and school shutdowns, there have been over 9,700 deaths in Nepal due to the coronavirus (Kumar, 2021). However, remote areas of the country are much more unsafe as there are not as many people who are educated about the dangers of the virus and the necessary precautions such as social distancing. This is because in rural areas, there is less access to the media, so inhabitants of these communities often do not know how to keep themselves safe. As a result, the fatality rate of infected patients due to the coronavirus is much higher in these remote areas (Farid et al., 2021). In addition, there are few medical resources available in rural communities; there is a short supply of hospital beds, ventilators, oxygen, and more. According to recent studies, Nepal only has one doctor per 10,000 people (Atreya \& Nepal, 2020). In general, the medical system in Southeast Asia is so overburdened that even though they have $25 \%$ of the global population, they only have $10 \%$ of the global health workforce (Atreya \& Nepal, 2020). Since the COVID19 situation is so bad in the villages of Nepal, the government is working hard to ensure the number of cases does not increase in these areas. As a result, there are strict measures in place for these communities to keep the pandemic under control. So, while universities and schools are starting to open up for in-person learning in big cities such as Kathmandu, institutions in remote areas are still completely shut down.

\section{Education in Nepal}

In Nepal, there are a total of “ 35,055 schools including community (government), institutional (private) and traditional (religious) schools" (Nepal Ministry of Education, 2020). Of all students from Grade 1 to Grade 12, approximately 26\% attend institutional schools (Nepal Ministry of Education, 2020). In general, upper-class students often attend private schools whereas middle and lower-class students attend public schools. While there are many schools for students in primary and secondary education, there are only 11 universities throughout Nepal (Devkota, 2021). Schools for students in Grade 1 to Grade 12 are spread out throughout the country, however, they are much more sparse in rural communities. This poses an issue since it makes it less likely that children living in villages will receive a primary and secondary education.

However, for post-secondary education, this situation is much worse; the 11 universities are all spread out in urban and populated cities, which are very far from the remote areas of Nepal. This is problematic because those who live in rural villages often do not want to leave their home and family to go to live in the city to pursue higher education. One of the main reasons for this is that families who live in villages are often impoverished, and the cost of living is much higher in urban areas. Meaning, most students in rural areas could not afford to go to university since it is so expensive. This further propels the cycle of poverty and continues the massive wealth gap present in a country like Nepal. While students in urban areas are much more likely to obtain post-secondary education, those in rural areas continue to live in their villages after finishing Grade 12. Without proper post-secondary education, it is more difficult to find employment, especially in remote areas as there is limited opportunity for well-paying jobs. This, in turn, increases the chances of someone being impoverished. This is how the poverty cycle continues, and COVID-19 has only exacerbated this cycle as the effects of the pandemic are negatively impacting the education of low-income students in specific.

Students who live in rural areas are more likely to be illiterate and perform poorly in school. This is because their education is not as good as private schools or public schools in big cities. The leading reasons for this are that teachers are not as qualified and there are many students per class. Overall, the education system for students living in remote communities is much more inadequate than the education system in urban areas, and COVID-19 is further worsening their learning.

\section{Research Context and Methods}




\section{Context of Khamariya}

Khamariya is a small village located in the far western region of Nepal. This is one of the economically disadvantaged areas of Nepal; there is inadequate infrastructure, low-income families, and limited job opportunities. Khamariya is so remote that there are no population statistics or other information available on the community. There are few public schools nearby for primary and secondary school students, however, there are minimal, if any, private schools anywhere near this community.

Mainly impoverished families live in this rural community, and often the adults do not have proper education or well-paying jobs. There is a massive wealth gap between those who live within Khamariya and those who live in nearby cities outside Khamariya. There is limited access to technology in this village, so inhabitants often do not have internet, radios, or computers. The conditions are so bad that the electricity cuts out numerous times throughout the week.

The number of COVID-19 cases is high in this community, which is why strict measures are in place to keep schools closed. In Khamariya, people often live in joint families which means there are many members of the extended family living together under the same roof.

\section{Methods: Participants, Data Collection, and Analysis}

Participants were chosen based on two factors: age and the fact that they live in Khamariya, Nepal. 15 participants were selected, and they are all enrolled in upper-primary school. In order to obtain the sample for this study, the "snowball sampling technique" was used. This is where an existing study participant recruits new subjects through their connections and acquaintances (QuestionPro, n.d.). Then, those newly recruited subjects enlist more participants through their connections, and so on. This technique was used until 15 participants were recruited. This type of sampling is often used for "conducting qualitative research with a population that is hard to locate" (QuestionPro, n.d.).

Once the participants were chosen, the next step was to ensure there was parental consent as the participants are all minors. After this, data was collected through hour-long interviews with each individual subject. The interviews were completely anonymous, and any information the participant did not want shared remained confidential between the interviewer and interviewee. The participant was allowed to skip any question they did not feel comfortable answering, and they could stop the interview at any time they wished. The interviews were conducted in Nepali and translated to English to be studied. In addition, the interviews were carried out through whatever platform the participant preferred and had access to, such as Zoom or over a phone call. There were 17 interview questions in total, with seven being short-answer questions and ten being long-answer questions (see Appendix A for interview questions).

A qualitative analysis was conducted across the results of the interviews to find any major themes, patterns, and trends. The findings are discussed and analyzed below.

Table 1. Descriptive Statistics of Participants.

\begin{tabular}{|l|l|l|l|}
\hline Topic & Answers & N & $\%$ \\
\hline \multirow{2}{*}{ Gender } & Male & 6 & 40.0 \\
\cline { 2 - 5 } & Female & 9 & 60.0 \\
\hline \multirow{2}{*}{ Type of School } & Public & 15 & 100.0 \\
\cline { 2 - 5 } & Private & 0 & 0.0 \\
\hline \multirow{2}{*}{ Age } & 12 & 4 & 26.7 \\
\cline { 2 - 5 } & 13 & 6 & 40.0 \\
\cline { 2 - 5 } & 14 & 5 & 33.3 \\
\hline \multirow{2}{*}{ Grade } & 4 & 2 & 13.3 \\
\cline { 2 - 5 } & 5 & 5 & 33.3 \\
\hline
\end{tabular}




\begin{tabular}{|l|l|l|l|}
\hline \multirow{4}{*}{ Parents' Education } & 6 & 3 & 20.0 \\
\cline { 2 - 4 } & 7 & 5 & 33.3 \\
\hline \multirow{5}{*}{ Personal Technology } & At least one parent graduated middle school & 2 & 13.3 \\
\cline { 2 - 4 } & At least one parent graduated high school & 0 & 0.0 \\
\cline { 2 - 4 } & At least one parent graduated university & 0 & 0.0 \\
\cline { 2 - 4 } & Both parents received no formal education & 13 & 86.7 \\
\cline { 2 - 4 } & Desktop & 0 & 0.0 \\
\cline { 2 - 4 } & Laptop & 2 & 13.3 \\
\cline { 2 - 4 } & Tablet & 0 & 0.0 \\
\cline { 2 - 4 } & Phone & 2 & 13.3 \\
\cline { 2 - 4 } & No technology & 11 & 73.3 \\
\hline
\end{tabular}

\section{Findings and Analysis}

\section{Status of School Amidst the Pandemic}

When asked if their school is open during the pandemic for in-person or virtual learning, all 15 participants said their school is completely shut down. They have not been obtaining any formal education from their school in over a year since their schools closed on March 18, 2020. All 15 participants go to public schools which are government-funded and have limited resources and infrastructure to provide an adequate education during COVID-19. This is because most students who attend the public schools near Khamariya are low-income students who do not have access to personal technology such as laptops and tablets. Many participants directly said or alluded to the fact that their school lacks funding, and as a result, their education during the pandemic is suffering because of it.

Since the participants have not gone to school since lockdown in March 2020, many participants described feeling as if they are falling behind with their studies, and all participants said they do not fully remember the concepts they were learning before the pandemic started. These prolonged school closures have a detrimental effect on students' knowledge and skill development. Furthermore, a couple of participants discussed how they feel even further behind because private schools have been doing virtual learning throughout the pandemic, and recently, schools have started to open up again for in-person learning in big cities. So, while private-school and wealthy students are continuing to get an education, the participants and students similar to the participants in this study are lagging behind. This is increasing the gap between advantaged and disadvantaged children and, in turn, continues the cycle of poverty.

Participants also explained that some schools in urban areas with more funding are sending materials home to students so they can learn individually, but unfortunately, the schools near Khamariya do not have the infrastructure to coordinate this. 14 out of the 15 participants expressed a desire to be educated during COVID-19 as they loved classes and learning. However, the schools they currently attend simply do not have the funding and resources to provide any education during this time. What's more, none of the 15 participants had any access to a qualified tutor, leaving them without any formal education for over one year. One major implication of this is that it can leave lasting impacts on students' learning and well-being.

\section{Education in Khamariya before COVID-19}

In order to fully analyze how the education of students has been affected in Khamariya, Nepal, it is important to understand the education system before COVID-19.

The participants expressed that they were extremely grateful for the education they received prior to COVID19. The routine, consistency, and emotional stimulation allowed them to prosper in their studies, especially since obtaining an education was a privilege most of their parents did not get the opportunity to have. They described their 
classes as "engaging", "fun", and "interesting". Eight out of the 15 participants described their teachers as "qualified", and 12 of the participants said they liked their teachers. During school, students had classes such as Math, English, and Science. The students also loved the social component of school; they got to see their friends and interact with their peers every day. Students in Nepal normally go to school six hours a day for six days a week. To go from learning 36 hours a week to no formal education at all can be extremely detrimental to one's education and well-being.

While the participants thoroughly enjoyed their school and learning experiences, they did describe some disadvantages and limitations to the education they were receiving. The participants stated that they had to walk a long distance to get to their school as there were none in close proximity to their houses in the village. There were 30 to 40 students within each class which made it difficult for students to ask questions to the teacher and get one-on-one attention. This would sometimes result in participants falling behind during the lessons or being confused with homework. The large student-to-teacher ratio shows how the public school system is so overburdened in Nepal. The public school system does not have the infrastructure to create smaller class sizes as there are limited qualified teachers. This has major consequences since students are often less engaged in the learning material with bigger classes.

When asked what learning was like before COVID-19, all 15 participants said the majority of their learning was memorization, repetition, and recitation-based. They were required to remember many facts and recite passages. While this is effective as it allows students to practice their language skills and remember important information, this has its limitations. For example, their learning is not application-based, meaning they do not get to think for themselves, problem-solve, or use critical thinking skills. These skills are vital, especially if they join the workforce in the future. Without the proper development of these skills, it may be difficult for students to apply themselves and deal with certain difficult situations in the future. The education system in Nepal is often described as a "one size fits all" education where there is no personalized learning. However, "education is not merely about memorizing texts... it is about awakened intelligence and deep sensitivity to life" (Kharel, 2018).

Another flaw with the education system that the participants described is that there are many people of different ages in their grades; there were students in their classes with different levels of knowledge on certain subjects and concepts. The participants explained that this made it difficult for them to learn since sometimes, the lessons were too easy or too difficult for them.

As it is evident, the education system in Nepal before COVID-19 needed to be reformed. While "Nepal has made strides in education over the past decades" (Devkota, 2021), more can still be done to ensure equitable access to quality education. Even though the education system was not perfect, at least students were obtaining some sort of formal learning. Now, since learning has halted in certain areas of Nepal, the country has taken a massive step backwards with their education system. This is because transitioning back to school and getting students caught up with their learning when it is safe to return will be extremely difficult.

What's more, COVID-19 is amplifying the existing limitations within the education system in Nepal, and in turn, it is widening the gap between economically advantaged and disadvantaged. For example, while there were students at different levels in the same classes before the pandemic, the return to school will bring even more students who are at different levels. This is because, during the pandemic, some students remember what they learned before COVID-19, some students are self-studying, and some students are not studying at all. Every single student in Khamariya has a slightly different learning experience with their education during the pandemic. Since all or most of the students will be at different levels of each subject, it will be difficult for the students to learn the materials properly as it might be too easy or difficult for them. This hinders their access to quality education and can affect their longterm development of education.

\section{Personal Learning and Technology}

Only four out of the 15 participants responded that they have access to personal technology. Two of these four participants had a cell phone and the other two had a laptop. Three out of the four participants who have technology explained that their parents bought it for them during the pandemic so they could self-study and connect with their 
friends. These three participants explained that they had no prior knowledge of using technology, so it took them a long time to understand the different platforms, apps, and functions. Moreover, none of the participants had access to a radio or television.

The four participants who have technology expressed difficulty using it as their internet and Wi-Fi connection cut out often. However, all four of these participants discussed in their interviews that they used their technology to further their education. For example, it was used to self-study, connect with peers through online messaging, and watch informational videos online. One participant said that her technology allowed her to use her language skills as she messaged and interacted with friends and family in both English and Nepali. This is one of the many ways that technology has proved to be beneficial for educating students in Khamariya during the pandemic. Even though this technology is helping participants continue to learn and build up certain skills, it is in no way comparable to the formal education they were receiving prior to the pandemic.

The four participants who have technology said it has been useful during the pandemic as it allows them to feel more connected to their community, and it provides an avenue for them to keep in touch with their friends during COVID-19. Participants also explained that the technology helped to take care of their emotional well-being, especially during lockdown, because it helped them communicate with others whenever they felt lonely during the pandemic.

All four participants with technology explained that they often share their personal technology with their siblings and cousins who live in their household. This is because other children and family members often want to use the phone or laptop to connect with their own friends or use it to further their learning by watching informative videos and looking at online resources. Participants also explained that sharing the technology hindered their own personal learning during COVID-19 because their family frequently borrowed the phones or laptops when the participant was self-studying. Since the participants live in big, joint families who all use and share the technology, the participants have limited time with the phone or laptop to study and learn.

Even though some students who go to public schools near Khamariya have personal technology, most students do not. What's more, since public schools are so overburdened and underfunded, the schools cannot provide laptops or tablets to each of the students. This is why the public schools near this village do not offer forms of virtual learning. Another reason why remote learning is not occurring is because the schools themselves do not have the proper infrastructure to teach online. This is because most teachers do not know how to use technology, and internet connection is spotty in remote areas of the country (Surkhali \& Garbuja, 2020). In fact, only $13 \%$ of school facilities in Nepal have access to the internet (Nepal Ministry of Education, 2020). Due to these technological and internet barriers, the school has no way of communicating or contacting their students, so the students cannot receive any takehome materials such as worksheets and lessons from their teachers. As virtual learning requires technological facilities, those who do not have such resources are not getting access to a quality education during the pandemic and are instead getting left behind in their studies. This problem is mainly targeted towards impoverished students who live in rural communities as this demographic is least likely to have access to technology.

Almost all of the 11 participants who did not have any sort of personal technology said they were trying to study on their own without any formal education. Many of the participants without technology said they formed their own study-groups with their siblings and cousins who live in their house. They try to study Math and English together by giving each other practice questions. Most of the participants enjoy these study-groups with their family and friends because it is the only education they are receiving during COVID-19. It is an opportunity for students and children in the family to come together and collaborate with each other to help everyone learn. Within these study-groups, the students used low technology resources such as workbooks and textbooks to learn and practice concepts they were taught in school. Students in rural communities are so passionate about getting an education and furthering their learning during the pandemic that they are taking the initiative to study and teach themselves.

However, they did discuss some limitations to these study-groups. Since there is no teacher or qualified adult to help them learn, they have to come up with all the lessons and questions themselves, which can be quite difficult. Whenever they have questions that none of the study-group members can answer, they have no mentor or teacher to 
guide them. As well, with COVID-19 and lockdowns, family members are home more often. As a result, it is loud in the houses, which often makes it difficult to concentrate when studying with their group. Many participants said that another major disadvantage to these study-groups is that, since the groups consist of siblings and cousins, they are often all different ages. Due to this, the members of the study-groups are all at different levels in subjects like Math and English, which makes it difficult for the participants to study with their groups. These limitations hinder the learning that occurs during the study sessions, however, any education that impoverished students in rural areas can receive during this time is beneficial.

\section{Transitioning Back to School}

Another important aspect of this topic to consider is how students will be affected when they transition back to school after not receiving any sort of academic support or formal learning from their school for over a year.

All 15 participants expressed worry and fear for when they return to school because they are scared it will be difficult for them to catch up on all the classwork they missed over the past year. This is especially because many students forgot a lot of what they learned before COVID-19. While all the students are excited to go back to in-person learning when it is safe, it has been so long since schools shut down that transitioning back will majorly disrupt and change their daily lives. This is because students have spent the last year developing a new routine where education does not play such an important role. So much uncertainty and lack of consistency in a young child's life can have negative effects on their mental well-being.

As well, there is going to be a lot of pressure on teachers to make up for the time lost, which may include rushing through lessons or skipping over teaching concepts entirely (Dawadi et al., 2020). This can be detrimental to students' learning because if proper time is not given to teach each concept, students can easily get confused and fall even further behind. Often, concepts taught in Grades 1 to 8 build the foundation for students' learning and education in higher grades. So, if students do not have a strong foundation in basic concepts and subjects, it will affect their long-term education. This is because if students go to secondary school, it will be extremely difficult for them to understand what is being taught.

Five out of the 15 participants felt that the longer their school is shut down, the less likely they will actually return to school. This is because the participants have spent the last year in lockdown helping their family with housework and working on their family farms. Participants' parents have started to rely on the children to help around the house. The participants explained that they truly value family and want to prioritize their parents' needs. They think their parents will frown upon them spending 36 hours a week at school since their parents need their help, and the participants do not want to let their parents down.

Another reason why drop-out rates will increase is because it becomes difficult for students to re-engage in learning once one has been out of school for so long (Dawadi et al., 2020). Specifically, when thinking about Nepal, school drop-out rates will increase because many parents have lost their jobs and rely on their children to pick up on some of the responsibilities. Since Nepal is an agricultural country, "parents from rural localities may be reluctant to send their children back to school because they may prefer their children to continue to support them in farming and livestock herding" (Dawadi et al., 2020; Poudel \& Subedi, 2020). This can have major implications as it is continuing the cycle of poverty, especially in rural areas. A reason for this is that the school drop-out rate will be much higher in remote villages as compared to urban areas. This makes it extremely hard to put an end to poverty in rural communities because without proper education, it is difficult to get a well-paying job.

\section{Participants' Goals and Aspirations for their Education and Future}

The participants reported that COVID-19 did not affect their goals for the future for the most part. Most participants did not plan on graduating from high school, but instead, most students planned on the highest level they graduate to be Grade ten or lower. After graduation, participants had very traditional goals for their future based on their gender. 
The males either wanted to work in agriculture in the village or work abroad in bigger urban cities as security guards, taxi drivers, or domestic workers such as cooks. Most male participants did not want to wait to graduate high school because they want to work to support their families as soon as possible. On the other hand, the female participants wanted to raise a family and take care of household chores in the village of Khamariya.

Something interesting that was found is that the parents' education and job had an influence on the participant's aspirations and goals for the future. Most parents had no education; there were only two participants that had at least one educated parent. All of the participants' fathers either worked in urban areas of Nepal or India with lowincome jobs, or they worked in the fields in Khamariya growing crops. This is the future all of the male participants said they expected for themselves. None of the mothers of the participants had a job as they focused on raising their children and running the household. This is what most of the female participants expect their future to look like as well. Many participants did not see the value in getting educated past high school because they know they are likely going to take over responsibilities in the village or work low-income jobs in big cities which do not require an education. This continues the poverty in rural communities like Khamariya because students do not try to seek other opportunities in Nepal, but they instead stick to what they know and what they are comfortable with. This limits their chances of obtaining a proper income in the future.

There were only two participants who plan on getting some sort of post-secondary education, and coincidentally, both of those participants have at least one parent that graduated middle school. The other 13 participants do not plan on graduating high school, and none of the parents of these 13 participants got any sort of formal education. Therefore, a trend becomes apparent: those who have educated parents are more likely to pursue higher education.

\section{Benefits of the Pandemic: New Roles, Skills, and Values Acquired}

Since students are not going to school at all, they are spending their days doing other activities, hobbies, and work. Every single participant said that they had taken on a new role during the pandemic or that they learned new skills and values.

\section{Roles, Responsibilities, and Hobbies}

There were certain roles and hobbies that both men and women took up during COVID-19, and there were others that were specific to one's gender. For example, most participants, regardless of sex, started new hobbies such as yoga, meditation, and exercise. Many participants also turned to religion during COVID-19. These new hobbies that participants took up were used as a way to fill the students' time now that they were not going to school. Participants explained that yoga and exercise were used to keep in touch with one's body and to keep physically healthy. Meditation and religion were used to find inner peace and keep mentally healthy during the pandemic where there was a lot of uncertainty and the children's lives were disrupted. They found that these activities were very beneficial during the pandemic, and they said they would continue to practice these activities even if school starts up again.

While there were some activities that both girls and boys took part in during the pandemic, there were certain roles that were specific to each gender. The boys' roles and responsibilities revolved around working in agriculture. Since Khamariya is a rural community, each family has their own large plot of land. Most families use this land for growing crops as Nepal is an agricultural country (Poudel \& Subedi, 2020). Then, families will either use these crops to make their meals or sell these crops to earn an income. Agriculture is a massive component of the lives of the families that live in Khamariya, so it makes sense that parents would rely on their children to help out with it during COVID-19. The boys spend five hours per day on average working in the fields, which comes to a total of 35 hours a week. Since the male participants were spending so much time on this new role, they explained that they often had to stop their self-learning or their study-groups to go work in the fields. This shows that these new roles were taking priority over their studies, and in turn, hindering their education. Moreover, this new responsibility that many boys took up during COVID-19 is representative of what most male participants want to do in the future: agriculture. So, 
since they have gotten so much exposure to this type of work over the past year, this could be beneficial to them in the future if or when they go into this line of work.

On the other hand, female participants often filled their time with housework and taking care of the other children in the house. More specifically, their role included cooking different Nepali curries and other dishes, cleaning with a broom and mop, washing and folding clothes, making beds, and watching the children. Some of the female participants had no knowledge at all on how to do these activities whereas other participants had little knowledge on how to carry out these tasks. However, after the pandemic, the female participants were working on these roles much more, so they got the opportunity to learn more about how to take care of the household responsibilities. This experience can be beneficial especially in the future since many women explained that they are going to focus on maintaining a house and having a family once they grow up. The females spent an average of six hours a day doing these chores and tasks, and similar to the male participants, they reported that they often had to stop their self-studying or their study-group to tend to their household responsibilities. So much time was spent on these chores because many of the participants live in joint families which means many family members live under the same roof. There is especially more housework during COVID-19 because family members are home more often due to lockdowns.

While the participants learned new hobbies and obtained new roles which are beneficial, there are still some limitations to this. In Nepal, there are very traditional values on the roles of men and women, and that is evident in the responsibilities each gender was given during the pandemic. Males did work to support the family while women did household tasks. When thinking about the wider scope and long-term, this can pose an issue. This is because the students grow up believing what they see and hear in their family structure. This confines them to their own specific role based on their gender, which means they have little to no opportunity to grow and break out of these gender roles. This continues the cycle of poverty especially for women whose role is often limited to taking care of the household. This is because while managing a family and household is admirable, it is difficult to make a living off of solely this role.

\section{Skills and Values}

In addition to new roles and responsibilities, all the participants believed they gained new skills and values during COVID-19. Some of the main values that participants explained they acquired include resilience and perseverance. This is because they had to remain mentally strong during a time of loneliness, uncertainty, and pain. As well, six out of the 15 participants reported that their fathers work in urban cities as domestic workers in Nepal and India such as Kathmandu, Surat, and Mumbai. Because of COVID-19, it was unsafe for the fathers of the participants to travel back and forth between the Khamariya and where they work. As a result, many participants rarely got the opportunity to see their fathers during the pandemic. This can be problematic, especially for young children, since they need consistency and emotional support to thrive. Despite these difficulties, the participants learned how to remain resilient through the tough times.

Another value that the participants gained was optimism. They explained that they are making the best out of a bad situation by trying to educate themselves and keep busy. Moreover, because participants have acquired many new roles around the house, such as cooking and cleaning for females and working in agriculture for males, they explained that this allowed them to learn organizational and responsibility skills. This is because they had to ensure they woke up early and spent enough time during the day doing their work so that their tasks would be completed for each day.

Since many of the participants created study-groups or self-studied during the pandemic, this allowed them to gain problem-solving, critical thinking, and creativity skills. This is because, within the study-group, they had to come up with their own questions to ask each other, they had to plan the lessons or concepts they wanted to study, and they had to use the resources available to them, such as completed homework questions from before the pandemic. These study-groups or self-study sessions were very helpful in building up necessary skills which the students never 
had before. This is especially because the school system is repetition and memorization-based instead of applicationbased. The pandemic truly allowed students to gain skills that they never would have otherwise.

All the skills acquired, such as resilience, perseverance, organization, responsibility, problem-solving, critical thinking, and creativity skills, will all be extremely beneficial when the students return to school and in the long-term. This is because the participants are starting to think for themselves and learn how to react when certain situations or problems arise.

While the participants gained many new skills, for some participants, certain skills decreased. For example, all of the participants without technology explained that their social skills declined. This is because they were not able to communicate with their friends and peers daily, like they would have during school. This can be problematic because when students return to school, it might be difficult for them to converse comfortably with their peers. On the other hand, the four participants who do have technology did not report any increase or decrease in their social skills. This is because the technology allowed the students to connect with their friends even during COVID-19.

\section{Government Solutions and Shortcomings}

The Government of Nepal and organizations like UNICEF have put many plans in place to limit the negative effects COVID-19 is having on students' short and long-term education. In order to educate as many students as possible, the Government of Nepal is trying to use multiple delivery methods and a combination of digital and non-digital approaches to educate students during the pandemic (Thomas et al., 2020). They are doing this so that they can target students from different communities and economic backgrounds. Some of the solutions implemented in Nepal include radio-based learning, television-based learning, teaching through landline or mobile phones, online learning, or teaching through take-home packages and learning through worksheets that were given at the beginning of school closures (Chapagain \& Neupane, 2020).

When the participants were asked if their public schools have implemented any of these solutions, all participants said their school has not provided any of the support measures listed above. This is because remote areas are much less likely to have access to radios or televisions. As well, out of all public schools in Nepal, only $25 \%$ of children received learning support from teachers through phone calls or virtual learning, and those who are impoverished are less likely to receive help from teachers (Radhakrishnan et al., 2021). So, while the Government of Nepal has put many solutions in place to ensure there is continuous learning throughout the pandemic for all students, these measures are simply not enough as remote and impoverished communities are not benefiting from them at all. On the other hand, those who are wealthy or live in urban areas are far more likely to gain from these solutions. This further increases the gap between the advantaged and disadvantaged and makes it less likely to end the cycle of poverty in rural areas of Nepal.

\section{Limitations}

While the sample collection and data collection methods are used by many experts in qualitative research, there are still some limitations that need to be addressed. The sample size is only 15 students, which is quite small. This increases the chances of the findings and conclusions in this paper being less reliable. Another limitation is that the interviews were conducted in Nepali and translated to English to be analyzed. Due to this, there might have been some information that got lost in translation. Therefore, there is a slight chance that important information was left out of this paper. Moreover, there were two Zoom interviews and 13 phone interviews. Sometimes, because of spotty internet connection, the Zoom interviews would cut out and the researcher could not hear what was said by the participant. This, once again, could have led to some information being left out of this paper. For the 13 phone interviews, another limitation is that the researcher cannot be completely sure that it was the recruited participant who was talking. This increases the chances of the information presented in this paper being unreliable. 


\section{Future Research}

As a next step, possible future research includes sampling participants that live in rural areas other than Khamariya and comparing the results to see any similarities or differences. As well, students from urban areas can be sampled and interviewed to get a deeper insight as to how their education has been affected by the pandemic. Furthermore, to get a better understanding of how learning has been impacted by COVID-19, students can be sampled from a wider age range. Lastly, in the future, it would be interesting to see how the pandemic has affected the long-term education of students in rural communities.

\section{Conclusion}

As it is evident, COVID-19 has had a major impact on the education system in Nepal, especially for impoverished students in remote communities like Khamariya. Students have not been obtaining any formal education as their schools do not have the infrastructure to manage this. As a result, students have been attempting to self-study, however, this is not proving to be very useful. This will make the transition back to in-person learning very difficult as the students' have not been in the classrooms for over a year. While the education system in Nepal was not great before the pandemic, COVID-19 is exacerbating the negative aspects of the public education system. Furthermore, while the coronavirus has had major detrimental effects on learning for students in rural communities, there have been some benefits. Students are learning many new essential skills and taking on new roles that they never would have if they were in school.

While the sample was taken only from Khamariya, there are many other rural areas in Nepal where the conditions and socioeconomic backgrounds are extremely similar to the village studied. When thinking about this on a broader scale, this can have major repercussions. This is because most of the students in Nepal who are not getting any formal education come from impoverished families who live in remote communities. So, their education continues to dwindle while students in populated cities' education continues without any impediments. Students who are not learning are more likely to drop out of school and work to earn an income for their family or take care of their house. This continues the cycle of poverty because when the students grow up, it will be difficult for them to find a meaningful job, so they will continue to do what has been done for generations: working low-income jobs or doing housework.

\section{Acknowledgments}

I would like to thank my advisor, Ms. Andrea Charlton, for her guidance in completing this research project. Her unwavering support has been invaluable, and it is truly appreciated.

\section{References}

Acharya, A., Subedi, S., Lamichhane, G., Gyawali, N., Poudyal, N., Bastola, G., Bhattarai, B. R., Aryal, B., Adhikari, B., Marahatha, R., Bhatta, M., Paudel, M., \& Parajuli, N. (n.d.). Digital learning Initiatives, Challenges and Achievement in Higher Education in Nepal Amidst COVID-19. https://edarxiv.org/r85bc/download/?format=pdf

Atreya, A., \& Nepal, B. (2020). COVID-19 pandemic and Nepal. Medico-Legal Journal, 88(2), 102-103. doi: https://doi.org/10.1177/0025817220923690 
Chapagain, N. K. \& Neupane, U. (2020). Contextual learning: rethinking education for Nepal in the wake of COVID-19 crisis. Applied Science and Technology Annals, 1(1), 98-111. doi: https://doi.org/10.3126/asta.v1i1.30281

Dawadi, S., Giri, R., \& Simkhada, P. (2020). Impact of COVID-19 on the Education Sector in Nepal: Challenges and Coping Strategies. Advance. doi: https://doi.org/10.31124/advance.12344336.v1

Devkota, K. R. (2021). Inequalities reinforced through online and distance education in the age of COVID-19: The case of higher education in Nepal. International Review of Education, 67, 145-165. doi:

https://doi.org/10.1007/s11159-021-09886-x

Dreesen, T., Akseer, S., Brossard, M., Dewan, P., Giraldo, J., Kamei, A., Mizunoya, S., \& Ortiz J. (2020). Promising Practices for Equitable Remote Learning. Emerging lessons from COVID-19 education responses in 127 countries. Innocenti Research Briefs no. 2020-10, UNICEF Office of Research. https://www.unicef-irc.org/publications/1090promising-practices-for-equitable-remote-learning-emerging-lessons-from-covid.html

Farid, N., Hayes, B., \& Sirkhell, R. (2021, January 27). Nepal's Challenges in Delivering Education Amidst the COVID-19 Pandemic. Asia Pacific Foundation of Canada. https://www.asiapacific.ca/publication/nepals-challengesdelivering-education-amidst-covid-19

Gautam, D. K., \& Gautam, D. P. (2021). Transition to Online Higher Education during COVID-19 Pandemic: Turmoil and Way Forward to Developing Country of South Asia- Nepal. Journal of Research in Innovative Teaching \& Learning, 14(1). https://www.emerald.com/insight/content/doi/10.1108/JRIT-10-2020-0051/full/html

Kharel, S. (2018). Information and Communication Technology for the Rural Development in Nepal. Tribhuvan University Journal, 32(2), 177-190. doi: https://doi.org/10.3126/tuj.v32i2.24714

Kumar, R. (2021, July 27). More people are dying in remote villages due to limited health care, lack of testing and inequitable vaccination. Nepali Times. https://www.nepalitimes.com/banner/nepals-uneven-covid-19-deaths/

Larmar, S., Sunuwar, M., Sherpa, H., Joshi, R., \& Jordan, L. P. (2021). Strengthening community engagement in Nepal during COVID-19: community-based training and development to reduce child labour. Asia Pacific Journal of Social Work and Development, 31(1), 23-30. doi: https://doi.org/10.1080/02185385.2020.1833749

Nepal Ministry of Education. (2020, March). COVID-19 Education Cluster Contingency Plan, 2020. UNESCO. https://planipolis.iiep.unesco.org/es/node/6966

Poudel, K., \& Subedi, P. (2020). Impact of COVID-19 pandemic on socioeconomic and mental health aspects in Nepal. International Journal of Social Psychiatry, 66(8), 748-755.

doi: https://doi.org/10.1177/0020764020942247

QuestionPro. (n.d.). Snowball Sampling: Definition, Method, Advantages and Disadvantages. https://www.questionpro.com/blog/snowball-sampling/

Radhakrishnan, K., Angrist, N., Bergman, P., Cullen, C., Matsheng, M., Ramakrishnan, A., Sabarwal, S., \& Sharma, U. (2021, March 29). Learning in the Time of COVID-19: Insights from Nepal. World Bank.

https://openknowledge.worldbank.org/handle/10986/35384 
Shrestha, S., Haque, S., Dawadi, S., \& Giri, R. A. (2021). Preparations for and practices of online education during the Covid-19 pandemic: A study of Bangladesh and Nepal. Education and Information Technologies. doi: https://doi.org/10.1007/s10639-021-10659-0

Surkhali, B., \& Garbuja, C. K. (2020). Virtual Learning during COVID-19 Pandemic: Pros and Cons. Journal of Lumbini Medical College, 8(1). doi: https://doi.org/10.22502/jlmc.v8i1.345

Thomas, C. J. (2020, April 13). Coronavirus and challenging times for education in developing countries. Brookings. https://www.brookings.edu/blog/education-plus-development/2020/04/13/coronavirus-and-challengingtimes-for-education-in-developing-countries/

UNICEF. (2021, January 13). Government of Nepal and partners launch campaign to mitigate learning loss wrought by COVID-19. https://www.unicef.org/nepal/press-releases/government-nepal-and-partners-launchcampaign-mitigate-learning-loss-wrought-covid

World Bank. (2021, March 13). World Bank Education COVID-19 School Closures Map. https://www.worldbank.org/en/data/interactive/2020/03/24/world-bank-education-and-covid-19 